\title{
Incidences of caudal fin malformation in fishes from Jubail City, Saudi Arabia, Arabian Gulf
}

\author{
Laith A. Jawad, Mustafa Ibrahim, Baradi Waryani
}

Received - 18 August 2017/Accepted - 09 March 2018. Published online: 31 March 2018; Inland Fisheries Institute in Olsztyn, Poland Citation: Jawad L.A., Ibrahim M., Waryani B. 2018 - Incidences of caudal fin malformation in fishes from Jubail City, Saudi Arabia, Arabian Gulf - Fish. Aquat. Life 26: 65-71.

\begin{abstract}
These case studies endeavor to report incidences of caudal fin deformities in several commercial fishes living in natural populations in the Saudi Arabian coastal waters of the Arabian Gulf. Two groups of anomalies were observed, slight and severe. The carangid species, Parastromateus niger (Bloch) and the soleid species, Euryglossa orientalis (Bloch \& Schneider), had slight cases of caudal fin abnormalities, while the species Oreochrromis mossambicus (Peters), Epinephelus stoliczkae (Day), Diagramma pictum (Thunberg), Cephalopholis hemistiktos (Rüppell), Lethrinus nebulosus (Forsskål), and Lutjanus sanguineus (Cuvier) had severe deformities. The abnormalities were assessed by morphological diagnosis. None of the cases was fatal as they occurred in adult individuals. The possible causes for these deformities as well as the suitability of this kind of case study for environmental monitoring are discussed. Further studies should be conducted from the perspective of pollution.
\end{abstract}

Keywords: deformity, teleost fishes, slight abnormality, severe anomaly, oil pollution

\footnotetext{
L.A. Jawad [" $\left.\Xi^{\circ}\right]$

Flat Bush, Manukau, Auckland, New Zealand

e-mail laith_jawad@hotmail.com

M. Ibrahim

Ministry of Agriculture, Fish Welfare Branch, El-Jubail Province,

Saudi Arabia

B. Waryani

Department of Fresh Water Biology and Fisheries, University of

Sindh, Jamshoro, Sindh, Pakistan
}

\section{Introduction}

Aberrations in fish bodies have attracted the attention of researchers since the sixteenth century (Gudger 1936), and since then a large number of studies have documented the presence of various types of anomalies in wild fishes (Boglione et al. 2006, Jawad and Hosie 2007, Jawad and Öktoner 2007, Koumoundouros 2008, Orlov 2011, Jawad and Al-Mamry 2012, Rutkayová et al. 2016, Jawad et al. 2016). Fin anomalies are generally extremely well documented in both wild and reared fish (Divanach et al. 2016), and they include the absence of the tail or compression (Lemly 1993, Jawad 2014). The incidence of partial tails is very rare in wild fish populations (Orlov 2011, Divanach et al. 2016). During early life stages of fish and with the presence of unfavourable environmental conditions, such as pollution, skeletal deformities can occur (Bengtsson et al. 1988, Lemly 1993). In wild fishes, visible anomalies are usually encountered through fishing activities, angling, and scientific studies. Abnormal fishes can be used as indicators of water pollution because of their high incidence in polluted areas (Bengtsson et al. 1988).

A limited number of studies concerning caudal fin deformities have been published on the fishes of the northwest Indian Ocean region, the Sea of Oman, and 
the Arabian Gulf. They were reported from Kuwait by Almatar and Chen (2010), from the Sultanate of Oman by Jawad (2014) and Jawad and Al-Mamry (2012), and from Iran by Jawad et al. (2010). No studies of caudal fin deformities have been published on any fish species from the Arabian Gulf coasts of Saudi Arabia. Therefore, the aim of the present case studies were: (1) to report for the first time several caudal fin deformities observed in fishes from Saudi Arabia; (2) to describe these anomalies and compare them with those of normal individuals.

\section{Materials and methods}

The fish specimens with caudal fin deformities made available for these case studies are as follows: two specimens of the families Carangidae, Parastromateus niger (Bloch), one normal specimen $315 \mathrm{~mm}$ TL, $309 \mathrm{~mm}$ SL, one abnormal specimen 313, 302 mm; Cichlidae, Oreochrromis mossambicus (Peters), abnormal specimen $210 \mathrm{~mm}$ body length; Epinephelidae, Epinephelus stoliczkae (Day), 240 mm body length; Haemulidae, Diagramma pictum (Thunberg), one normal specimen $340 \mathrm{~mm}$ TL, 328 mm SL, four abnormal specimens 135 - $240 \mathrm{~mm}$ body length; Lethrinidae, Lethrinus nebulosus (Forsskål), normal specimen, 410 mm TL, 198 mm SL, abnormal specimen $415 \mathrm{~mm}$ TL, $404 \mathrm{~mm}$ SL; Lutjanidae, Lutjanus sanguineus (Cuvier), abnormal specimen $450 \mathrm{~mm}, 438 \mathrm{~mm}$ SL; Serranidae, Cephalopholis hemistiktos (Rüppell), normal specimen, 415 mm, $403 \mathrm{~mm}$ SL, abnormal specimen, 410 mm TL, 399 mm SL; Soleidae, Euryglossa orientalis (Bloch \& Schneider), normal specimen 235 mm TL, $224 \mathrm{~mm}$ SL, abnormal specimen $233 \mathrm{~mm}$ TL, 222 $\mathrm{mm}$ SL. The fishes were caught in the period from March 10, 2015, to November 18, 2016, in the waters of Jubail City, Saudi Arabia. The specimens of $O$. mossabicus brought from the Sultanate of Oman were collected from lagoons. The specimens were collected by local fishermen using drift gill nets. Normal specimens were obtained from the same fishing catches at the same fishing locality to make comparisons. Bodies and fins were examined carefully for external parasites, malformations, amputations, and any other morphological anomalies. In the measurement of the fish samples, the size of the individuals that had lost their caudal fin completely was referred to as body length.

\section{Results}

Description of caudal fin deformities. Caudal fin deformities of the 11 deformed specimens examined were divided into two categories based on the complexity of the case. The slight deformity group includes those cases where part of the caudal fin was damaged. The severe deformity group was represented by specimens that presented with the absence of the whole caudal fin with the underneath supporting bony structures. In all cases observed, no scars were noted in the healed injured area.

\section{Slight deformity}

\section{Family: Carangidae}

Parastromateus niger (Figures 1A-B). The normal caudal fin in this species had upper and lower lobes of nearly equal size. In the anomalous specimen, the upper lobe of the caudal fin was smaller than the lower lobe by about $50 \%$. The length of the fin rays in the deformed lobe graduated in length dorsally and ventrally, with normal tips. No other anomalies were noted.

\section{Family: Soleidae}

Euryglossa orientalis (Figures 1C-F). The deformed caudal fin in this specimen had constrictions both dorsally and ventrally at its base. It was different in shape to the normal caudal fin in this species, where its outer contour is continuous with those of the dorsal and anal fins. The caudal fin rays were clumped together and not clearly separated. The blind side of the fish showed that the posterior anal fin rays were slightly deformed with a curved shaped, and the 


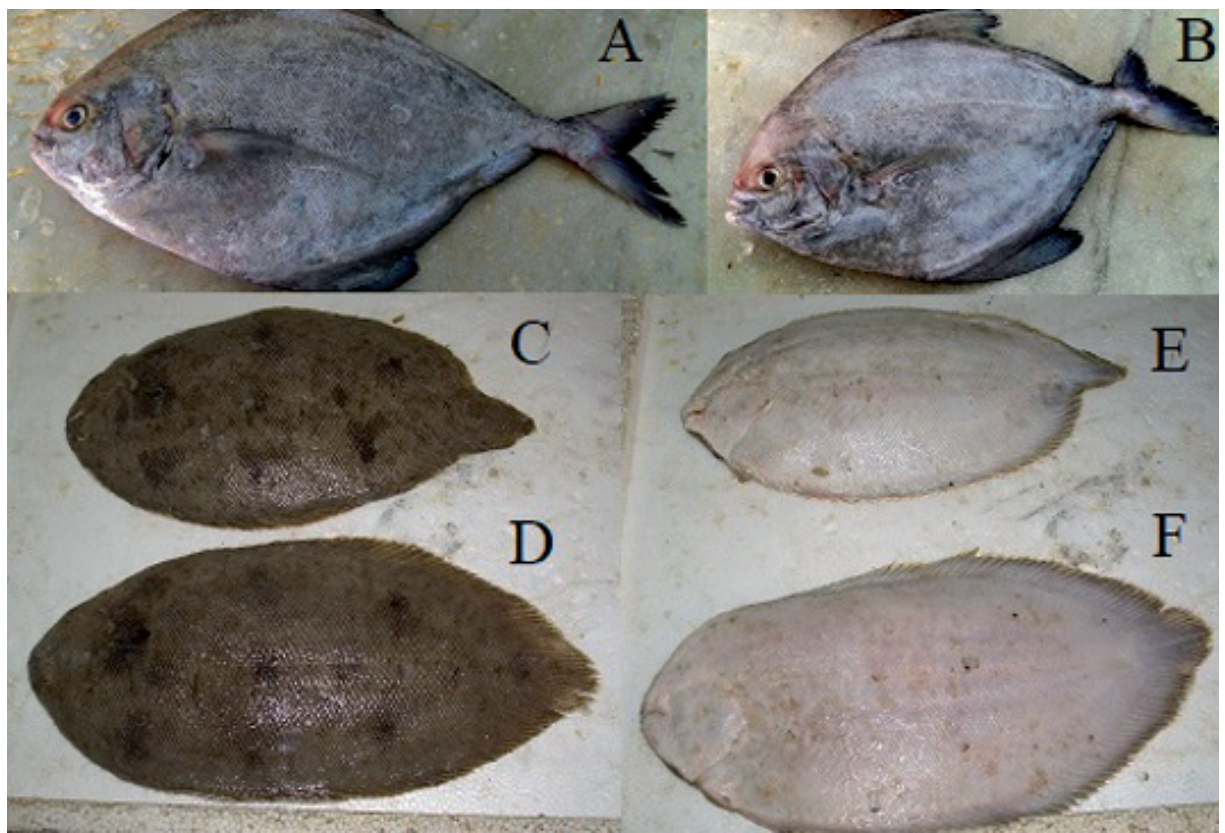

Figure 1. Parastromateus niger, A - normal specimen, 315 mm TL, 309 mm SL; B - abnormal specimen, 313 mm TL, 302 mm SL; Euryglossa orientalis, Eyed side. C - abnormal specimen, $233 \mathrm{~mm}$ TL, $222 \mathrm{~mm}$ SL; D - normal specimen, $235 \mathrm{~mm}$ TL, 224 mm SL; Blind side. E - abnormal specimen, 233 mm TL, 222 mm SL; F - normal specimen, 235 mm TL, 224 mm SL.

caudal fin looked much smaller than the normal caudal fin. No other anomalies were observed.

\section{Severe deformity}

\section{Family: Cichlidae}

Oreochromis mossambicus, abnormal specimen 210 mm body length (Figures 2A). In this specimen, a complete absence of the caudal fin with its supporting skeletal elements and the caudal peduncle area of the vertebral column were evident. The deformed area reached the posterior edge of both the dorsal and anal fins. In the normal specimen there were 15-18 dorsal soft fin rays, while in the deformed specimen there were 11 soft rays, with the $11^{\text {th }}$ ray exhibiting a slight abnormality. The anal fin rays were complete in number as in the normal specimen. No other abnormalities were noted.

\section{Family: Epinephelidae}

Epinephelus stoliczkae (Figure 2B). In this anomalous specimen, the whole caudal fin and the underneath supporting skeleton together with the caudal peduncle part of the vertebral column were absent. The posterior end of the fish was rounded, and the tissues in this area formed a ball-like shape around the posterior end of the fish. The deformed area did not reach the posterior edges of the dorsal and anal fins. No other deformities were noted.

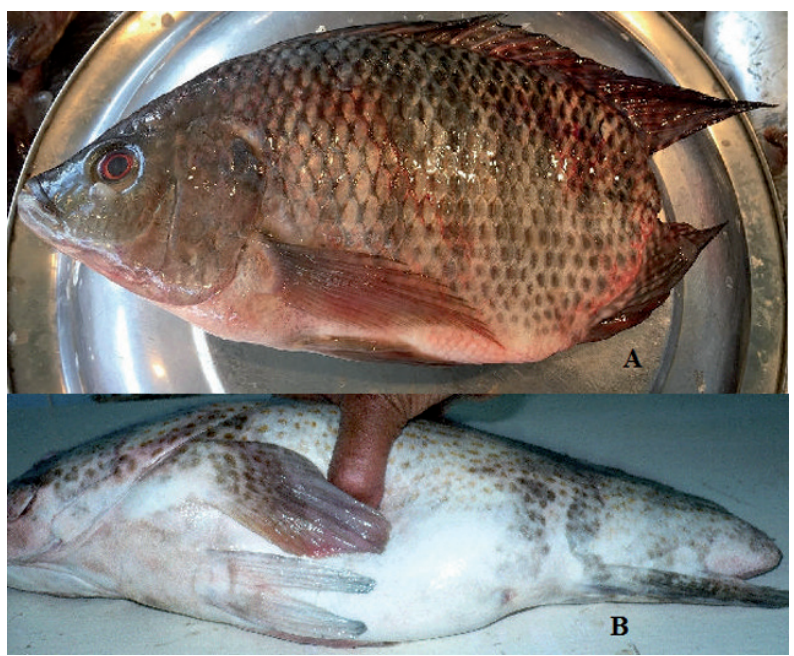

Figure 2. Oreochrromis mossambicus, A - abnormal specimen, 210 mm SL; Epinephelus stoliczkae, B - abnormal specimen, 240 $\mathrm{mm}$ SL. 


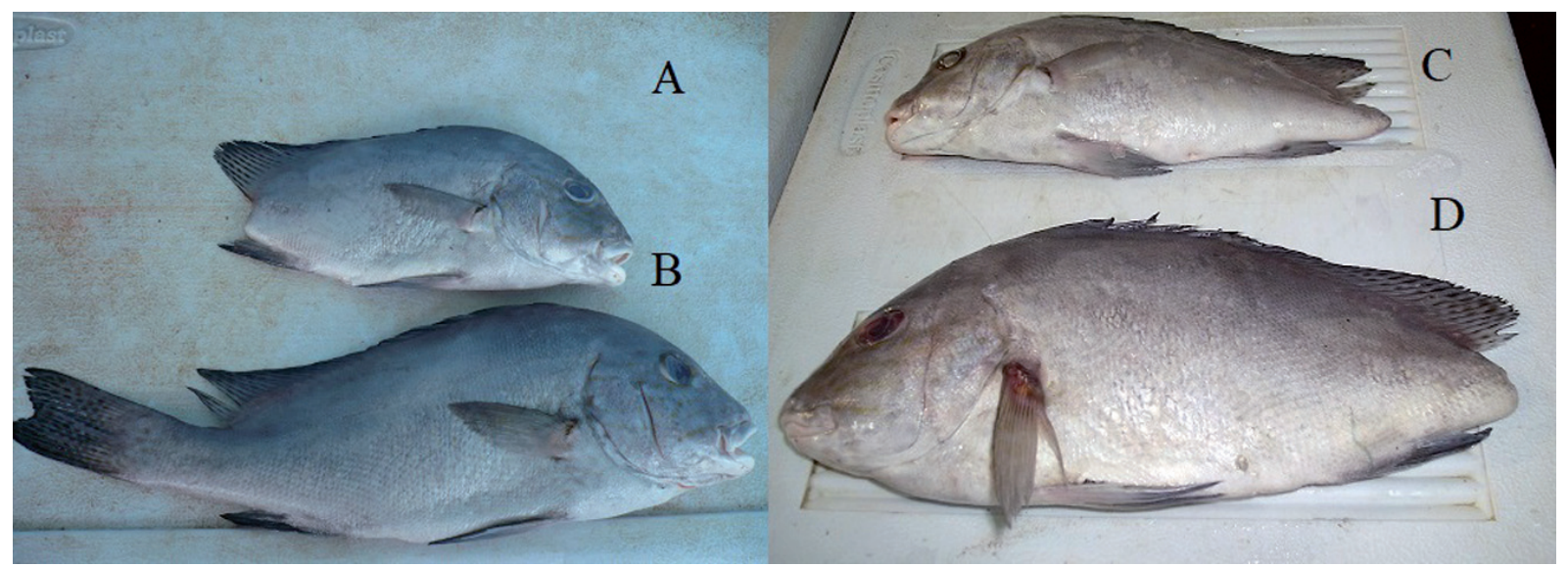

Figure 3. Diagramma pictum, A - abnormal specimen, $135 \mathrm{~mm}$ SL; B - normal specimen, $340 \mathrm{~mm}$ TL, $328 \mathrm{~mm}$ SL; C - abnormal specimen, 210 mm SL; D - abnormal specimen $210 \mathrm{~mm}$ TL, $328 \mathrm{~mm}$ SL.

\section{Family: Haemulidae}

Diagramma pictum (Figures 3A-D and 4A-B). In this species, there were four specimens with no caudal fins. Comparing the deformed specimens with the normal one (Figure 3b), it appeared that the affected areas in them did not extend back to the posterior edges of the dorsal and anal fins. Therefore, the soft rays of these fins were not affected by this deformity. The complete absence of the caudal fin also involved the complete absence of the caudal skeleton and the caudal peduncle area of the vertebral column. The internal viscera of the deformed specimens examined were normal and the gonads were developing very well. No other anomalies were observed in the deformed specimens.

\section{Family: Serranidae}

Cephalopholis hemistiktos (Figures 4C-D). In these specimens, half of the caudal fin was present. In this species, the caudal fin has a rounded posterior end, with straight ending fin rays. The lower lobe of this fin was completely absent with the underneath supporting skeleton. The fin rays in the upper lobe appeared deformed and clumped together. No other morphological anomalies were noted.

\section{Family: Lethrinidae}

Lethrinus nebulosus (Figures 4E-F). The shape of the caudal fin in the normal specimen was bifurcated and lunate. In the deformed fish, the lower lobe of the caudal fin was incomplete. The missing part was the ventral anterior part of the fin. The deformity was mild in severity as the muscles in the disturbed area seemed to be affected. Some of the short caudal fin rays were left in place without any deformity. No other deformities were observed.

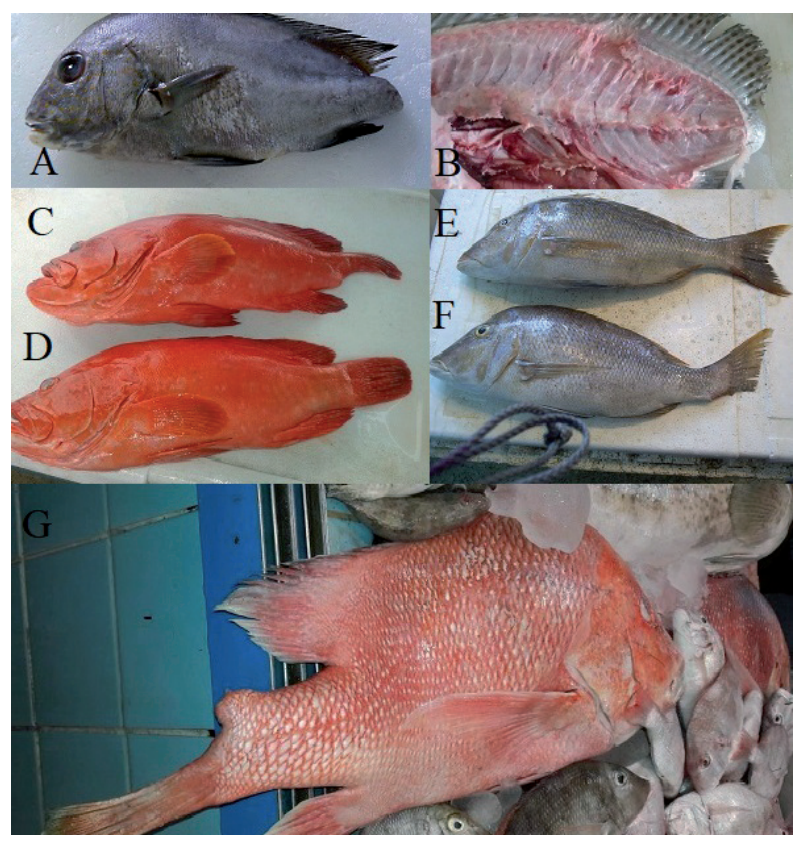

Figure 4. Diagramma pictum, A - abnormal specimen, $198 \mathrm{~mm}$ SL; B - dissected specimen, $198 \mathrm{~mm}$ SL; Cephalopholis hemistiktos. C - abnormal specimen, 410 mm TL, 399 mm SL; D normal specimen, $415 \mathrm{~mm}, 403 \mathrm{~mm}$ SL; Lethrinus nebulosus, E normal specimen, $410 \mathrm{~mm}$ TL, $356 \mathrm{~mm}$ SL; F - abnormal specimen, 415 mm TL, 404 mm SL; Lutjanus sanguineus, G - abnormal specimen, $450 \mathrm{~mm}, 438 \mathrm{~mm}$ SL. 


\section{Family: Lutjanidae}

Lutjanus sanguineus (Figure 4G). In this deformed specimen, the complete upper lobe of the caudal fin was missing along with its underneath supporting skeleton. The $1^{\text {st }}$ and $2^{\text {nd }}$ hypural bones were enlarged and had a rounded shape. The deformed area involved the caudal fin, and the caudal peduncle was normally developed. No other teratogens were noted.

\section{Discussion}

This is the first examination of case studies to investigate the type of caudal fin anomalies that are observed in adult wild teleosts fish species from the Arabian Gulf in general and Saudi Arabian waters in particular. The aim was to identify teratogenic caudal fins in the specimens of the species studied and to identify a possible relationship between these deformities and several types of environmental factors such as pollutants. Several fish species from a wide taxonomic spectrum that exhibited caudal fin abnormality and were collected from the same geographical area could explain the suggestion put forth by Browder et al. (1993).

Although there are a large number of studies on fin anomalies worldwide, the percentage of aberrations for each fin is not available. In general, the distribution of the fin deformities can be considered to be second to vertebral column abnormalities in fish, which comprise $13 \%$ of malformed vertebral columns described (Galván-Magańa et al. 1994). In aquaculture, it is possible to estimate the incidences of anomalies in certain fins (Koumoundouros 2010).

Caudal fin deformities can developed as a result of the abnormal bending of the posterior end of the notochord during the yolk-sac stage in the early life history of fish before the development of the caudal skeleton (Koumoundouros et al. 1997). Therefore, the fish specimens examined in the present case studies could have been living for several years with these abnormalities, and this kind of malformation would not have interfered with biological activities, such as feeding (Ribeiro-Prado et al. 2008). The different caudal fin anomalies were not fatal, but we do not know if they affected mobility in some way. The pectoral fins were found to be in apparently perfect condition, but not the caudal fin, which did not have the characteristic shape of that in normal individuals.

The important roles of maneuvering and steering in fishes are assigned to the caudal fin. Therefore, it must be structured so as to cope with hydrodynamic pressures with the least possible expenditure of energy (Boglione et al. 1993, Lauder 2000). Any deformity in the caudal fin will hamper the flexibility of the tail, thus impairing the performance of the fish including the capacity to avoid predators. Weihs (1972) and Webb $(1973,1977)$ suggest that metabolic rates and metabolic scope are not affected by the amputation or absence of part of the caudal fin in fish. Therefore, the metabolic power made available to the muscular system will be the same in normal and deformed specimens. Also, these authors found that critical speed was not considerably reduced by the partial absence of caudal fin lobes, but it was reduced drastically when the caudal fin was completely absent. Schäperclaus et al. (1992) suggests that there are five major classes of possible causes of fish malformations: hereditary factors, damage during embryonic development, injuries, diseases, and damage stemming from environmental factors. In the current study, the specimens presenting with no caudal fin could have been attacked by predators during the juvenile stage because of the well healed tip of the posterior end of the vertebral column, but without further information; however, we are unable to support this hypothesis. Usually, fish that survive injuries encounter several other problems such as blood loss, overcoming osmotic disturbances, infections, slow healing, avoidance of predators, hunger, and great changes in the ability to swim (Gunter and Ward 1961). Consequently, the status of such fish anomalies in the Arabian Gulf area needs to be evaluated continually and accurately.

Disturbances in environments inhabited by fish can be traced and monitored through the development of different deformities that can signal the existence of ecosystem disruptions. Therefore, it is 
important to make people are aware of how healthy the environment is in which they live.

In nature, several potential factors can cause caudal fin deformities including the effects of light and heat exposure during reproduction (Koo and Johnston 1978) and heavy metal pollution (Slooff 1982). Water temperatures in the Arabian Gulf vary widely throughout the year, which induce variations in water oxygen levels. This variation is very clear during the summer when temperatures and salinity are at their highest levels (Al-Ansi et al. 2002, Mohamed and Mesaad 2007, Al-Thukair et al. 2007, Dawoud 2012). Further studies should be conducted from the perspective of pollution, especially of the port of Jubail City, which is the largest Saudi Arabian industrial and commercial port on the Arabian Gulf coast where thousands of oil barrels and hundreds of tons of commercials goods from oil super tankers and commercial vessels, respectively, are handled daily. The adverse effects of this maritime activity on the marine environment of the waters in the vicinity of Jubail City have altered it into a heavily polluted habitat (El Samra et al. 1986, Cross 1992, Reynolds 1993, Massoud et al. 1996, Barth 2003, Bejarano and Michel 2010).

Generally, morphological deformities can negatively impact economic outcomes through reduced fish weight, and, more importantly, from a much reduced value per $\mathrm{kg}$ of slaughtered fish. Therefore, further efforts to improve fisheries management should be made to explore the various etiological causes of deformities before further critical choices are made.

Acknowledgements. We would like to thank the Ministry of Agriculture, Fish Welfare Branch, Jubail Province, Saudi Arabia for giving us the opportunity to examine and study the deformed fish specimens. Our thanks are also due to Sergey Bogorodsky of the Station of Naturalists, Omsk, Russia and Ronald Fricke of Staatliches Museum für Naturkunde, Rosenstein, Germany, and William Smith-Vaniz, Florida Museum of Natural History, for identifying the fish species.

Author contributions. L.A.J. designed the research and wrote the manuscript; M.I. collected the specimens and took photos; B.W. assist in the analysis of the images.

\section{References}

Al-Ansi M.A., Abdel-Moati M.A.R., Al-Ansari I.S. 2002 Causes of fish mortality along the Qatari waters (Arabian Gulf) - Intern. J. Environ. Stud. 59: 59-71.

Almatar S., Chen W. 2010 - Deformities in silver pomfret Pampus argenteus caught from Kuwait waters - Chin. J. Oceanol. Limnol. 28: 1227-1229.

Al-Thukair A.A., Abed R.M.M., Mohamed L. 2007 - Microbial community of cyanobacteria mats in the intertidal zone of oil-polluted coast of Saudi Arabia - Mar. Pollut. Bull. 54: 173-179.

Barth H.J. 2003 - The influence of cyanobacteria on oil polluted intertidal soils at the Saudi Arabian Gulf shores Mar. Pollut. Bull. 46: 1245-1252.

Bejarano A.C., Michel J. 2010 - Large-scale risk assessment of polycyclic aromatic hydrocarbons in shoreline sediments from Saudi Arabia: Environmental legacy after twelve years of the Gulf war oil spill - Environ. Pollut. 158: 1561-1569.

Bengtsson Å., Bengtsson B.E., Lithner G. 1988 - Vertebral defects in fourhorn sculpin, Myoxocephalus quadricornis L., exposed to heavy metal pollution in the Gulf of Bothnia - J. Fish Biol. 33; 517-529.

Berra T.M., Au R.J. 1981 - Incidence of teratological fishes from Cedar Fork creek, Ohio - Ohio J. Sci. 81: 225-229.

Boglione C., Costa C., Giganti M., Cecchetti M., Di Dato P., Scardi M., Cataudella S. 2006 - Biological monitoring of wild thicklip grey mullet (Chelon labrosus), golden grey mullet (Liza aurata), thinlip mullet (Liza ramada) and flathead mullet (Mugil cephalus) (Pisces: Mugilidae) from different Adriatic sites: meristic counts and skeletal anomalies - Ecol. Indic. 6: 712-732.

Boglione C., Marino G., Bertolini B., Rossi A., Ferreri F., Cataudella S. 1993 - Larval and postlarval monitoring in sea bass: morphological approach to evaluate finfish seed quality - In: Production, Environment and Quality (Eds) G. Bamabe, P. Kestemont, European Aquaculture Society. Special Publication No. 18, Ghent, Belgium: 189-204.

Browder J.A., McClellan D.B., Harper D.E., Kandrashoff M.G. 1993 - A major developmental defect observed in several Biscayne Bay, Florida, fish species - Environ. Biol. Fishes 37: 181-188.

Cross A.M. 1992 - Monitoring marine oil pollution using AVHRR data: observations off the coast of Kuwait and Saudi Arabia during January 1991 - Int. J. Remote Sen. 13: 781-788. 
Dawoud M.A. 2012 - Environmental impacts of seawater desalination: Arabian Gulf case study - Intern. J. Environ. Stud. 1: 22-27.

Divanach P., Boglione C., Menu B., Koumoudouros G., Kentouri M., Cataudella S. 1996 - Abnormalities in finfish mariculture: an overview of the problem, causes and solutions - In: Seabass and seabream culture: Problem and prospects (Eds) B. Chantain, M. Saroglia, J. Sweetman, P. Lavens, International Workshop. Verona, Italy. October 16-18, 1996. European Aquaculture Society, Oostende, Belgium, 21 p.

El Samra M.I., Emara H.I., Shunbo F. 1986 - Dissolved petroleum hydrocarbon in the north-western Arabian Gulf Mar. Pollut. Bull. 17: 65-68.

Galván-Magańa F., Rodríguez-Romero J., Abitia-Cárdenas L.A. 1994 - First record of abnormal vertebral column in the green bar snapper Hoplopagrus guentheri (Osteichthyes: Lutjanidae) - Rev. Biol. Trop. 4: 388-389.

Gudger E.W. 1936 - Beginnings of fish teratology - Sci. Mon. 43: 252-261.

Gunter G., Ward J.W. 1961 - Some fishes that survive extreme injuries, and some aspects of tenacity of life Copeia 4: 456-462.

Jawad L.A. 2014 - Caudal Fin Deformity in the Wild Silver Pomfret Pampus argenteus collected from the Arabian Gulf Coasts of Oman - Int. J. Mar. Sci. 4: 1-4.

Jawad L.A., Al-Mamry J.M. 2012 - Caudal fin deformity in mullet, Moolgarda pedaraki (Valenciennes, 1836) (Pisces: Mugillidae) - Croat. J. Fish. 70: 25-29.

Jawad L.A., Hosie A. 2007 - On the record of pugheadedness in snapper, Pagrus auratus (Forster, 1801) (Perciformes, Sparidae) from New Zealand - Acta Adriat. 48: 205-210.

Jawad L.A., Öktoner A. 2007 - Incidence of lordosis in the freshwater mullet, Liza abu (Heckel, 1843) collected from Ataturk Dam Lake, Turkey - An. Biol. 29: 105-113.

Jawad L.A., Fjelldal P.G., Hansen T. 2016 - First report on vertebral abnormality in the fivebeard rockling Ciliata mustela (Linnaeus, 1758) (Osteichthyes: Lotidae) from Masfjorden, Western Norway - Mar. Biodivers. doi:10.1007/s12526-016-0545-7.

Jawad L.A., Sadighzadeh Z., Valinassab T. 2010 - Malformation of the caudal fin in the freshwater mullet, Liza abu (Actinopterygii: Mugilidae) collected from Karkheh River, Iran - An. Biol. 32: 11-14.

Koo T.S.T., Johnston M.L. 1978 - Larva deformity in striped bass, Morone saxatilis (Walbaum), and blueback herring, Alosa aestialis (Mitchell), due to heat shock treatment of developing eggs - Environ. Pollut. 16: 137-149.

Koumoundouros G. 2008 - First record of saddleback syndrome in wild parrotfish Sparisoma cretense (L., 1758) (Perciformes, Scaridae) - J. Fish Biol. 72: 737-741.
Koumoundouros G. 2010 - Morpho-anatomical abnormalities in Mediterranean marine aquaculture - In: Recent Advances in Aquaculture Research (Ed.) G Koumoundouros, Transworld Research Network, Kerala, India: 125-148.

Koumoundouros G., Gagliardi F., Divanach P., Boglione C., Cataudella S., Kentouri M. 1997 - Normal and abnormal osteological development of caudal fin in Sparus aurata L. fry - Aquaculture 149: 215-226.

Lauder G.V. 2000 - Function of the caudal fin during locomotion in fishes: kinematics, flow visualization, and evolutionary patterns - Am. Zool. 40: 101-122.

Lemly A.D. 1993 - Teratogenic effects of selenium in natural populations of freshwater fish - Ecotox. Environ. Safe. 26: 181-204.

Massoud M.S., Al-Abdali F., Al-Ghadban A.N., Al-Sarawi M. 1996 - Bottom sediments of the Arabian Gulf-II. TPH and TOC contents as indicators of oil pollution and implications for the effect and fate of the Kuwait oil slick Environ. Pollut. 93: 271-284.

Mohamed Z.A., Mesaad I. 2007 - First report on Noctiluca scintillans blooms in the Red Sea off the coasts of Saudi Arabia: consequences of eutrophication - Oceanologia 49: 337-351.

Orlov A.M. 2011 - Record of a tailless Richardson's ray Bathyraja richardsoni (Garrick, 1961) (Rajiformes: Arhynchobatidae) caught off the Mid-Atlantic ridge Pan-Am. J. Aqua. Sci. 6: 232-236.

Reynolds R.M. 1993 - Physical oceanography of the Gulf, Strait of Hormuz, and the Gulf of Oman-Results from the Mt Mitchell expedition - Mar. Pollut. Bull. 27: 35-59.

Ribeiro-Prado C.C., Oddone M.C., Bueno-González M.M., Ferreira-De Amorim A., Capapé C., 2008 - Morphological abnormalities - Arq. Cięn. Mar. Fortaleza 41: 21- 28.

Rutkayová J., Jawad L., Nebesářová J., Beneš K., Petrášková E., Näslund J. 2016 - First records of scale deformities in seven freshwater fish species (Actinopterygii: Percidae and Cyprinidae) collected from three ponds in the Czech Republic - Acta Ichthyol. Piscat. 46: 225-238.

Schäperclaus W., Kulow H., Schreckenbach K. 1992 - Fish Disease - A.A. Balkema, Rotterdam, the Netherlands.

Slooff W. 1982 - Skeletal anomalies in fish from polluted surface waters - Aqua. Toxicol. 2: 157-173.

Webb P.W. 1973 - Effects of partial caudal-fin amputation on the kinematics and metabolic rate of under yearling sockeye salmon (Oncorhynchus nerka) at steady swimming speeds - J. Exp. Biol. 59: 565-581.

Webb P.W. 1977 - Effects of median-fin amputation on fast-start performance of rainbow trout (Salmo gairdneri) - J. Exp. Biol. 68: 123-135.

Weihs D. 1972 - A hydrodynamical analysis of fish turning manoeuvres - Proc. R. Soc. B-Biol. Sci. 182: 59-72. 